\title{
Enthalpies of Solution of the Nucleic Acid Bases. 2. Thymine in Water
}

\author{
Marthada V. Kilday \\ Center for Thermodynamics and Molecular Science, National Bureau of Standards, Washington, D.C. 20234
}

(June 19, 1978)

\begin{abstract}
An adiabatic solution calorimeter was used to measure enthalpies of solution in water of 8 samples of thymine for which analytical data are reported. Our best values for the enthalpy of solution and the change in heat capacity are

$$
\begin{gathered}
\Delta H^{\circ}(\infty, 298.15 \mathrm{~K})=(24.32 \pm 0.70) \mathrm{kJ} \cdot \mathrm{mol}^{-1} \\
\Delta C_{p}^{\circ}=(106 \pm 26) \mathrm{J} \cdot \mathrm{mol}^{-1} \cdot \mathrm{K}^{-1}, 298 \mathrm{~K}<\mathrm{T}<328 \mathrm{~K} .
\end{gathered}
$$

These were used to calculate $\Delta S^{\circ}=(53.1 \pm 3.6) \mathrm{J} \cdot \mathrm{mol}^{-1} \cdot \mathrm{K}^{-1}$ for the entropy of solution, and $C_{p 2}^{\circ}=(256 \pm 26)$ $\mathrm{J} \cdot \mathrm{mol}^{-1} \cdot \mathrm{K}^{-1}$ for the apparent molal heat capacity at infinite dilution. No change in the enthalpy of solution with concentration was observed in the range of 5 to $35 \mathrm{mmol} \cdot \mathrm{kg}^{-1}$.

Key words: Calorimetry; 5-methyl-2,4 (1H, 3H)-pyrimidinedione; 5-methyluracil; nucleic acid bases; thermochemistry; thymine: density, enthalpy of solution.
\end{abstract}

\section{Introduction}

This is the second in a series of papers on enthalpies of solution of the bases of the nucleic acids. The first paper reported on the enthalpy of solution of adenine in water $[1]^{1}$ and described many procedural details also followed in this work. Emphasis is placed on the characterization of the samples in order to establish realistic uncertainty limits for the measured values.

Thymine, a pyrimidine base, has the following structural formula [2]:<smiles></smiles>

It is slightly soluble in water $\left(\sim 4 \mathrm{~g} \cdot \mathrm{L}^{-1}\right.$ at $\left.298 \mathrm{~K}[3,4,5]\right)$. It sublimes and decomposes before it melts. The only measurements of the enthalpy of solution reported previously were by Alvarez and Biltonen [6].

${ }^{1}$ Figures in brackets indicate the literature references at the end of this paper.
In this work enthalpies of solution of four samples from three commercial sources (including a portion of the sample used by Alvarez and Biltonen) were compared. Enthalpies of solution were also measured for samples that were products of sublimation and of recrystallization from water and from ethyl alcohol. Measurements were made over the temperature range 297 to $328 \mathrm{~K}$ and over the concentration range 5 to 35 $\mathrm{mmol} \cdot \mathrm{kg}^{-1}$.

\section{The Thymine (Thy) Samples}

Enthalpies of solution were measured for four commercial samples $^{2}$ as received or after vacuum drying at $373 \mathrm{~K}$. The following information about these samples was obtained from labels, catalogs, and brochures supplied by the manufacturers or distributors:

Thy 1. Calbiochem, Cat. No. 6090, Grade A, 100 g received about 1970-exact date unknown. Label information: Lot 900490; Analysis: Nitrogen, 22.08 percent; Spectra at $\mathrm{pH} 7,250 / 2600.69 ; 280 / 2600.53 ; \lambda$ $\max 264 \mathrm{~m} \mu, \epsilon \max 7830$; Chromat. Homogeneous.

Thy 2. 9.4 g received from R. L. Biltonen, July 1974, from sample used in [6]. Distributed by Mann Research Laboratories, Cat. No. 2802, Lot R1282, Paper Chr.: Homogeneous.

\footnotetext{
2 The information presented in this paper is in no way intended as an endorsement nor a condemnation of any of the materials or services used. Commercial sources are named only for specific identification.
} 
Thy 3. E-M Laboratories, Cat. No. 8209, for biochemistry, Lot 495554l, 100 g received August 1947. Brochure information: Type analysis: assay, 98 percent (ref. to dried substance). Optical properties, Measured values $\mathrm{pH} 7: \lambda \max 264.5 ; \mathrm{E}_{250} / \mathrm{E}_{260} 0.67 \pm 0.02 ; \mathrm{E}_{280} / \mathrm{E}_{260} 0.53 \pm 0.01$; $\mathrm{E}_{290} / \mathrm{E}_{260} 0.09 \pm 0.02$. Thin layer chromatography, Layer: TLC plates Silica Gel $\mathrm{F}_{254}$ pre-coated. Solvent: 1-Propanol/water (70/30). $R f$ value: $\sim 0.75$.

Thy 4. Same as Thy 3 except E-M Laboratories Lot 4958785, $10 \mathrm{~g}$ received January 1975.

Portions of Thy 3 were further purified in this laboratory as follows:

Thy 3a. Approximately $22 \mathrm{~g}$ of Thy 3 was dissolved in $0.8 \mathrm{~L}$ of boiling distilled $\mathrm{H}_{2} \mathrm{O}$ and several grams of decolorizing activated charcoal was added. The hot solution was filtered into a heated filtration flask through a Nalgene Buchner funnel with No. 1 Whatman paper under No. 50 Whatman paper which was covered by a mat of filter paper pulp. The filtrate was reheated and passed through the same filter three times to remove traces of the charcoal and pulp. The final filtrate was transferred to a crystallizing dish and cooled slowly at about $295 \mathrm{~K}$. The needlelike crystals which formed were filtered through No. 1 Whatman paper and then redissolved in about $0.4 \mathrm{~L}$ of boiling distilled $\mathrm{H}_{2} \mathrm{O}$. As before, the hot solution was filtered and cooled slowly. The crystals which formed in the second recrystallization were filtered and dried at $340 \mathrm{~K}$ at atmospheric pressure for about $72 \mathrm{~h}$. The yield was $6.6 \mathrm{~g}$.

Thy 3b. Approximately $8 \mathrm{~g}$ of Thy 3 was dissolved in $0.5 \mathrm{~L}$ of hot 90 percent ethyl alcohol $(\mathrm{EtOH})$ and filtered through the filter described above. After cooling slowly, the large star-shaped crystals which formed were filtered on No. 1 Whatman paper. These crystals were redissolved, filtered, and recrystallized a second time. After filtering, this product was dried as described for Thy $3 \mathrm{a}$. The yield was $1.2 \mathrm{~g}$.

(Thy $3 \mathrm{a}$ and $\mathrm{b}$ were further dried under vacuum at $375 \mathrm{~K}$ for $134 \mathrm{~h}$ during volatile matter observations to be discussed in section 2.1.1.)

Thy 3d. $5 \mathrm{~g}$ of Thy 3 was slowly vacuum-sublimed according to the procedures described for Ade $1 c$ and $5 c$ [1]. The maximum temperature was about $410 \mathrm{~K}$ but most of the sublimation occurred at $390 \mathrm{~K}$. After 6 days the sublimation was stopped before all of the sample had sublimed. The sublimed sample and the residue of sublimation were removed from the sublimation vessel in a glove box guarded from atmospheric $\mathrm{H}_{2} \mathrm{O}$. Calorimetric samples were also transferred to the sample holder in this glove box. The sublimed sample was light and fluffy, and static-charge problems were encountered in transfers of the samples.

Thy 3e. This was the unsublimed residue from the sublimation of Thy 3 d.

All of the samples were white powders; Thy 1 had the finest granules and Thy 2 had a grey cast and was more inclined to stick together in lumps than the other samples.

\subsection{Characterization of Samples}

The purity of the bases of the nucleic acids cannot be determined from freezing temperature measurements because they decompose before melting. A less desirable alternative is to determine impurities in the samples and to describe the properties of the samples by various chemical and physical methods. In this laboratory the density of the thymine samples was measured, volatile matter was determined by vacuum drying, $\mathrm{H}_{2} \mathrm{O}$ by Karl Fischer titration, and impurities by paper and thin layer chromatography (TLC). Greater detail about these methods was given previously [1]. Analyses of the elemental compositions, emission spectra, and $\mathrm{x}$-ray diffraction patterns were obtained from other laboratories. The heat capacity of the crystalline samples at $298 \mathrm{~K}$ was also measured.

\subsubsection{Density, Volatile Matter, and $\mathrm{H}_{2} \mathrm{O}$}

The benzene displacement method of measuring densities was described [1]. The insolubility of thymine in benzene was confirmed by observing that there was (1) no change in the thymine mass as a result of the density measurement and (2) no visible residue when the benzene from the density measurement was evaporated to dryness. There was difficulty in wetting the samples with the benzene, and errors due to trapped air may have resulted. The measured densities were as follows: $1.341,1.328,1.372$, and $1.344 \mathrm{~g} \cdot \mathrm{mL}^{-1}$ for Thy $1,2,3$, and 4 (approximate sample mass: $0.6,0.4,1.3$, and $0.7 \mathrm{~g})$, respectively. The nearly linear relationship between the measured density and the mass of sample indicates a probable systematic error (such as air entrapment); however, the mean density value of $1.35 \mathrm{~g} \cdot \mathrm{mL}^{-1}$ was used to calculate the buoyancy correction factor, 1.0007 , for this work. This density is less than that of $(1.455 \pm 0.005) \mathrm{g} \cdot \mathrm{mL}^{-1}$ obtained on single crystals by the floatation method [7].

Samples of Thy 1 vacuum-dried at $340 \mathrm{~K}$ (see [1] for details) were at essentially constant mass after $4 \mathrm{~h}$ with a loss of only $0.5 \mathrm{mg} \cdot \mathrm{g}^{-1}$; at $375 \mathrm{~K}$, similar samples appeared to be at constant mass after about $8 \mathrm{~h}$ with a loss of $1.0 \mathrm{mg} \cdot \mathrm{g}^{-1}$; Thy 3 showed similar losses. However, Thy 2 did not reach constant mass at $340 \mathrm{~K}$; even after approximately $170 \mathrm{~h}$ the rate of mass loss was $0.6 \mathrm{mg} \cdot \mathrm{g}^{-1} \cdot \mathrm{h}^{-1}$. It was observed that Thy 4 lost mass at the constant rate of only $0.1 \mathrm{mg} \cdot \mathrm{g}^{-1} \cdot \mathrm{h}^{-1}$ for approximately $170 \mathrm{~h}$. The recrystallized samples, Thy $3 \mathrm{a}$ and $3 \mathrm{~b}$, showed a constant rate of mass loss of 0.025 $\mathrm{mg} \cdot \mathrm{g}^{-1} \cdot \mathrm{h}^{-1}$. It is assumed that these constant rates are all sublimation losses and not $\mathrm{H}_{2} \mathrm{O}$ or other impurities in the samples since the rates remained essentially constant from the beginning of the heating. The different rates are probably related to the different surface areas since Thy 2 which had the highest sublimation rate was the finest powder, and the coarse products of recrystallization had the lower sublimation rates.

Karl Fischer titrations of water in samples of Thy 1, 2, 3, and 4 indicated $0.12,0.18,0.12$, and 0.16 mass percent $\mathrm{H}_{2} \mathrm{O}$, respectively. A Karl Fischer automatic titrator with a $1-\mathrm{mL}$ automatic buret and recorder were used in the titrations. The reagent was calibrated before and after each group of measurements by addition of $1 \mathrm{~mL}$ of distilled $\mathrm{H}_{2} \mathrm{O}$ to the $50 \mathrm{~mL}$ of ACS spectroscopic methanol which was the solvent 
for the 50-mg samples of thymine. Approximately $30 \mathrm{~min}$ was required for complete solution. Dry nitrogen was continuously passed over the solution during the titrations. The estimated limit of detection under these conditions is about $0.02 \mathrm{mg}$ of $\mathrm{H}_{2} \mathrm{O}$.

A sample of Thy 4 which had been vacuum-dried at $375 \mathrm{~K}$ for $12 \mathbf{h}$, showed no gain in mass when exposed to the atmosphere ( $\sim 35 \%$ relative humidity) for $24 \mathrm{~h}$. This agreed with the findings of Falk [8] that no hydrates of thymine are formed at relative humidities as high as 93 percent. Therefore, because thymine was not hygroscopic, the calorimetric samples were transferred to the sample holder in the laboratory atmosphere except the products of sublimation where the transfers were made in the glove box.

\subsubsection{Other Analytical Work}

Emission spectroscopic analyses ${ }^{3}$ of Thy 1, 2, 3, and 4 indicated the same background limits of detection as for the adenine samples [1]. In addition, the following impurities were found in Thy 1 (in mass \%): Si, 0.15; Fe, 0.05; and traces of $\mathrm{Cu}$ and $\mathrm{Mg}$. The possible presence of these impurities is assumed to contribute no significant error to the enthalpy of solution.

The duplicate elemental analyses ${ }^{4}$ of Thy 1, 2, 3, and 4 as received are given in table 1 . The $H$ values for all of the samples agree with the theoretical value for anhydrous thymine; the $\mathrm{C}, \mathrm{O}$, and $\mathrm{N}$ for Thy 1,3 , and 4 are a little

${ }^{3}$ Analyses by J. A. Norris, Center for Analytical Chemistry, National Measurement Laboratory.

${ }^{4}$ Analyses by Micro-Analysis, Inc., Wilmington, DE 19808. high; and the $\mathrm{C}, \mathrm{O}$, and $\mathrm{N}$ for Thy 2 are significantly lower than those for anhydrous thymine. None of our other analytical data provides an explanation for the latter results which certainly indicate an undefined impurity. The analyses do, however, eliminate the possible presence of hydrates in the samples in significant amounts.

The guidelines set forth in a National Academy of Sciences (NAS) publication [9] were followed in our TLC and paper chromatographic work. Details of our procedures and preliminary tests of sensitivities and backgrounds were described in the first paper of this series [1].

Approximately $32 \mathrm{mg}$ of Thy 1, 2, 3, and 4 were each dissolved in $25 \mathrm{~mL}$ of hot $\mathrm{NH}_{4} \mathrm{OH}\left(\mathrm{aq}, 2 \mathrm{~mol} \cdot \mathrm{L}^{-1}\right) .5 \mu \mathrm{L}$ aliquots were taken for the spottings which contained about $6 \mu \mathrm{g}$ of thymine. A "standard" reference solution in $\mathrm{NH}_{4} \mathrm{OH}$ $\left(\mathrm{aq}, 1 \mathrm{~mol} \cdot \mathrm{L}^{-1}\right)$ was prepared which contained $5 \mathrm{mmol} \cdot \mathrm{L}^{-1}$ of adenine, cytosine, thymine, and uracil; this standard was run with each group of the thymine solutions.

$R_{f}$ values $=$ (distance traveled by major component $/$ distance traveled by the solution front) are given in table 2 for the four thymine samples on glass TLC plates coated with MN300F Cellulose (with fluorescent indicator), on Whatman No. 1 chromatography paper, P-1, and on Whatman No. 40 chromatography paper, $\mathrm{P}-40$, in the four carrier solutions listed. The NAS values from similar systems are also listed for comparison. Our values on P-40 (also used by NAS) are as much as $0.1 R_{f}$ unit higher than the NAS value-the results using $\mathrm{P}-\mathrm{l}$ are in better agreement with those of NAS. However, these are in acceptable agreement for independent measurements.

Table 1. Elemental analyses of thymine samples

\begin{tabular}{|c|c|c|c|c|c|c|c|c|}
\hline Substance & $\begin{array}{c}\text { Empirical } \\
\text { Formula }\end{array}$ & $\begin{array}{l}\text { Molecular } \\
\text { Mass }\end{array}$ & c & H & 0 & $\begin{array}{c}\mathrm{N} \\
\text { (Kfeldah } 1)\end{array}$ & $\begin{array}{c}\text { Sulfated } \\
\text { Ash }\end{array}$ & $\Sigma$ \\
\hline & & $\mathrm{g} / \mathrm{mo} 1$ & \multicolumn{6}{|c|}{ mass percent } \\
\hline \multicolumn{9}{|c|}{ Theoretical Composition: } \\
\hline Thy & $\mathrm{C}_{5} \mathrm{H}_{6} \mathrm{~N}_{2} \mathrm{O}_{2}$ & 126.1146 & 47.62 & 4.80 & 25.37 & 22.21 & ----- & 100.00 \\
\hline Thy $\cdot \mathrm{H}_{2} \mathrm{O}$ & $\mathrm{C}_{5} \mathrm{H}_{8} \mathrm{~N}_{2} \mathrm{O}_{3}$ & 144.1298 & 41.67 & 5.59 & 33.30 & 19.44 & ---- & 100.00 \\
\hline \multicolumn{9}{|l|}{ Analyses: } \\
\hline \multirow[t]{2}{*}{ Thy 1} & ---- & ------ & 48.09 & 4.76 & 25.89 & 22.37 & 0.24 & 101.35 \\
\hline & ----+--- & - - & 47.92 & 4.72 & 25.65 & 22.12 & 0.26 & 100.67 \\
\hline \multirow[t]{2}{*}{ Thy 2} & --- & ------ & 46.49 & 4.72 & 24.71 & 21.39 & 0.03 & 97.34 \\
\hline & --.--- & --- & 46.62 & 4.62 & 24.53 & 21.49 & 0.08 & 97.34 \\
\hline \multirow[t]{2}{*}{ Thy 3} & ------- & ------ & 47.87 & 4.72 & 25.48 & 22.57 & 0.00 & 100.64 \\
\hline & ----- & ----- & 47.93 & 4.81 & 25.57 & 22.39 & 0.03 & 100.73 \\
\hline \multirow[t]{2}{*}{ Thy 4} & -- & -- - & 47.77 & 4.82 & 25.56 & 22.64 & 0.01 & 100.80 \\
\hline & - & ---- & 47.95 & 4.74 & 25.27 & 22.83 & 0.00 & 100.79 \\
\hline
\end{tabular}


The four carrier (or tank) solutions, A, B, C, and D, are described in the footnote in table 2 . With solution $A$, the standard reference solution produced three distinct spots: one at the $R_{f}$ for adenine, one at the $R_{f}$ for uracil, and one at the $R_{f}$ 's for thymine and cytosine which were undistinguishable in this solution. With solutions B and C cytosine and uracil were undistinguishable at nearly the same $R_{f}$, but thymine and adenine formed separate spots. With solution D all three of the pyrimidine bases were undistinguishable; only adenine formed a separate spot.

The four thymine samples gave the same $R_{f}$ values within the reading uncertainty of approximately $\pm 0.02 R_{f}$ unit. No spots were visible except those of the major component in any of the chromatograms of the thymine solutions. We assume that 5 percent impurity would have been detected for any of the compounds listed on pages 153 and 154 of the NAS publication [9]. From these observations we estimate that the purity of the four thymine samples as received was 95 percent or more.

\subsubsection{Calorimetric Characterization}

Alvarez and Biltonen [6] reported (151.4 \pm 0.4 ) $\mathrm{J} \cdot \mathrm{mol}^{-1} \cdot \mathrm{K}^{-1}$ for the heat capacity of the crystalline Thy 2 at $298 \mathrm{~K}$. A comparable value, $(150.4 \pm 0.5) \mathrm{J} \cdot \mathrm{mol}^{-1} \cdot \mathrm{K}^{-1}$ [10], for Thy 3 was measured by Ernesto Friere using a drop microcalorimeter at the University of Virginia. The latter is considered to be the better value because results presented in this paper indicate that Thy 3 is probably of higher purity.

Table 2. $\mathrm{R}_{\mathrm{f}}$ values for the thymine samples in $\mathrm{NH}_{4} \mathrm{OH}\left(\mathrm{aq}, 2 \mathrm{~mol} \cdot \mathrm{L}^{-1}\right.$ ) solutions on fluorescent TLC plates and two papers
with four carrier solutions, $\mathrm{A}, \mathrm{B}, \mathrm{C}$, and $\mathrm{D}$.

\begin{tabular}{|c|c|c|c|c|c|c|c|c|c|c|c|c|}
\hline \multirow{2}{*}{$\begin{array}{l}\text { Thymine } \\
\text { Sample No. }\end{array}$} & \multicolumn{3}{|c|}{$A^{a}$} & \multicolumn{3}{|c|}{$\mathrm{B}^{\mathrm{a}}$} & \multicolumn{3}{|c|}{$c^{a}$} & \multicolumn{3}{|c|}{$D^{a}$} \\
\hline & TLC & $\mathrm{P}-1$ & $P-40$ & TLC & $\mathrm{P}-1$ & $P-40$ & TLC & $P-1$ & $P-40$ & TLC & $\mathrm{P}-1$ & $P-40$ \\
\hline 1 & 0.81 & 0.79 & 0.84 & 0.72 & 0.68 & 0.73 & 0.80 & 0.80 & --- & 0.88 & 0.78 & 0.79 \\
\hline 2 & .81 & .80 & .83 & .70 & .69 & .72 & .80 & .79 & -- & .91 & .75 & .78 \\
\hline 3 & .81 & .79 & .83 & .71 & .66 & .73 & .81 & .79 & -- & .89 & .75 & .82 \\
\hline 4 & .81 & .79 & .82 & .70 & .70 & .72 & .81 & .78 & -- & .87 & .79 & .77 \\
\hline NAS [10] & & & 0.78 & & & 0.63 & & & 0.72 & & & -- \\
\hline
\end{tabular}

\footnotetext{
${ }^{a}$ The compositions of the carrier (or tank) solutions was as follows:

Soln A: 5 parts of iso-butyric acid +3 parts of $\mathrm{NH}_{4} \mathrm{OH}\left(\mathrm{aq}, 0.5 \mathrm{~mol} \cdot \mathrm{L}^{-1}\right.$ ).

Soln B: 7 parts of iso-propyl alcohol +1 part of conc. $\mathrm{NH}_{4} \mathrm{OH}+2$ parts of $\mathrm{H}_{2} \mathrm{O}$.

Soln C: 7 parts of $95 \%$ ethyl alcohol +3 parts of sodium acetate (aq, $1 \mathrm{~mol} \cdot \mathrm{L}^{-1}$ ).

Soln D: $\mathrm{H}_{2} \mathrm{O}$ adjusted to $\mathrm{pH} 10$ with $\mathrm{NH}_{4} \mathrm{OH}\left(\sim 1\right.$ drop of conc. $\mathrm{NH}_{4} \mathrm{OH}$ in $300 \mathrm{~mL} \mathrm{H}_{2} \mathrm{O}$ ).
}

\section{Enthalpy of Solution}

Measurements of the enthalpy of solution of thymine in water were made in a platinum-lined, adiabatic solution calorimeter which was previously described in detail [11]. The solution capacity is approximately $300 \mathrm{~mL}$, and the volume of the platinum sample container (see [11]) used in this work was $2.7 \mathrm{~mL}$.

A fast stirring rate, 860 revolutions $\cdot \min ^{-1}$, was used to reduce the difficulty in wetting the sample. There was a tendency for the thymine to remain unreacted in air bubbles which stuck to the inner surface of the sample holder. Sometimes the air bubbles released upon opening the sample holder, carried some of the thymine to the surface of the solution where it floated or even bounced above the solution surface causing some of the sample to stick to the cover of the vessel. This problem was greatly reduced after the installation of a bronze sieve-wire baffle under the surface of the solution. The baffle did not significantly limit the stirring of the solution, but it did inhibit the air bubbles from carrying thymine above the solution surface. Occasionally however, some of the material escaped around the edges of the baffle. In a preliminary experiment, a wetting agent (Triton X-100) was added to the initial calorimetric solution, but there appeared to be no improvement in the wetting of the thymine sample.

In 10 of the 26 experiments reported here, some unreacted sample was visible at the end of the experiment-either stuck on the vessel cover, floating on the surface of the solution, or trapped in air bubbles adhering to the sample holder surface. However, the quantity of unreacted material in these experiments was estimated to be $<1 \mathrm{mg}$ and the deficiency in the heat of reaction was apparently within the calorimetric uncertainty. In a private communication, R. L. 
Biltonen stated that similar problems were encountered in their work [6], and an experiment was rejected if there was visible unreacted sample at the end of an experiment. However, their samples were in the 20- to 30-mg range and visible material would represent a larger fraction of the total heat of reaction than in our work where the samples were in the 0.2- to 1.3-g range. Biltonen also suspected some improvement in the completeness of reaction after the samples were vacuum dried; we found that this made little if any difference. Further observations regarding factors influencing completeness of reaction will be described in the discussion of the experimental data later in this section.

In each experiment there was an electrical calibration before and after the chemical reaction. In most of the experiments electrical energy was added during the endothermic reactions of thymine in water to prevent a decrease in the calorimeter temperature (hence, loss of adiabatic conditions). However, in a few experiments where the heat absorbed during the reaction was expected to be less than $100 \mathrm{~J}$ or the reaction was expected to be slow, electrical energy was not added during the chemical reaction. The energy absorbed was compensated for by the stirring energy, thus maintaining the calorimeter temperature and adiabatic conditions. Details of procedures and calculations were described previously [11, 12].

Measurements of the $\mathrm{pH}$ of stirred thymine solutions (25 $\mathrm{mmol} \cdot \mathrm{kg}^{-1}$ ) in equilibrium with air (as were the calorimetric solutions) indicated a $\mathrm{pH}$ of 5.6 with an estimated uncertainty of $0.1 \mathrm{pH}$ unit for both Thy 1 and Thy 3 . The meter was calibrated with a standard buffer at $\mathrm{pH} 7.0$ and was checked at the end of the measurements.

Uncertainties in this paper are at the 95 percent confidence level except as noted. The calorimetric experiments were completed between June and September 1976 although the preparational and analytical work began nearly 2 years earlier. The Table of Atomic Weights 1975 [13] was used in calculating the molecular masses used in this work: Thy, 126.1146; and $\mathrm{H}_{2} \mathrm{O}, 18.0152$. The calibrations of the quartz oscillator thermometer system and of the reference standards for electrical energy measurements are the same as described in the first paper of this series [1]. For conversions of energy units, 1 thermochemical calorie $=4.184$ joules.

\subsection{Calorimetric Experiments}

The data for enthalpy of solution measurements of 8 thymine samples, described in section 2 , are given in table 3 . The calorimetric measurements were made on Thy 1,2 , and 4 as received except that they were vacuum dried for 14 $\mathrm{h}$ at about $340 \mathrm{~K}$ and then for $10 \mathrm{~h}$ at about $373 \mathrm{~K}$; Thy 3 was used as received without vacuum drying. Portions of Thy 3 were twice recrystallized from distilled $\mathrm{H}_{2} \mathrm{O}$ (Thy $3 \mathrm{a}$ ), and from 90 percent ethyl alcohol (Thy 3b), and sublimed under vacuum at about $400 \mathrm{~K}$ (Thy $3 \mathrm{~d}$ ) with an unsublimed residue from the sublimation (Thy 3e). The calorimetric samples were transferred to the platinum sample holder in the atmosphere (relative humidity $=0.35 \pm 0.10$ and temperature $=295.5 \pm 1.0 \mathrm{~K}$ ) except the sublimation products, Thy $3 \mathrm{~d}$ and $3 \mathrm{e}$, which were transferred in a glove box containing a desiccant.

There was a significant difference in the reaction rates of the various samples in $\mathrm{H}_{2} \mathrm{O}$. It can be seen in table 3 that at $313 \mathrm{~K}$ the reaction period for Thy 1,2 , and $3 \mathrm{e}$ was 2 to $4 \mathrm{~h}$, for Thy 3, 3a, and 3b, about $0.5 \mathrm{~h}$; and for Thy $3 \mathrm{~d}$ and 4,1 to $2 \mathrm{~h}$. At lower temperatures the reaction periods were longer. The reaction periods in the experiments marked with an asterisk, where a small amount of unreacted sample was visible at the end of the measurements, were no longer than comparable experiments in which the reaction was apparently complete; thus incomplete reaction is not the cause of the different reaction rates. The last three experiments with Thy 3 show that the sample size has little effect on the duration of the reaction period.

In preliminary experiments using Thy 1 (not given in table 3 ) it became apparent that high stirring speed $(860 \mathrm{rpm})$ and relatively high temperature of reaction $(\sim 310 \mathrm{~K})$ greatly reduced the amount of undissolved material remaining at the end of the experiments. However, the problem was greater with Thy 2 which was sticky and tended to form agglomerates even after vacuum drying. The sample was sieved and only a small amount of Thy 2 was visible at the end of the three experiments given in table 3 . The samples were between standard sieve sizes 35 and 100 in Expts. No. 1165 and 1166, and less than standard sieve size 100 in Expt. No. 1167. In Expt. No. 1166 and subsequent experiments the sieve-wire baffle was installed under the solution surface; this reduced the probability of sample being carried to the surface by air bubbles. None of the other samples was sieved. There was no evidence of incomplete reaction at the end of experiments with the two recrystallized samples, with the unsublimed residue of sublimation, or with Thy 4. Our analytical data do not explain these differences in the solution behavior of the various samples.

In table 3, the Experiment Number is a serial number for experiments with this calorimeter and indicates the chronological order of the experiments. The Reaction Period is the elapsed time between initiating the reactions and the beginning of the rating period which follows the reaction. $\mathrm{T}_{\text {reaction }}$ is the mean of the initial and final temperatures of reaction. The estimated calorimetric uncertainty for an experiment, Cal. Unc., is based on the duration of the reaction, the magnitude of the temperature change from the reaction, and the standard deviation of the slope of the rating period following the reaction (see [1] for details). The heat of the solution reaction, $Q$ reaction, is given by the following equation: 


$$
Q_{\text {reaction }}=\Delta T_{\text {reaction }}\left(\frac{\epsilon_{i}+\epsilon_{f}}{2}\right)-q_{\text {vap }}
$$

where the electrical energy equivalents (in $\mathrm{J} \cdot \mathrm{K}^{-1}$ ) of the initial and final systems are $\epsilon_{i}$ and $\epsilon_{f}$, the temperature change due to the solution reaction is $\Delta T_{\text {reaction, and the }}$ heat of vaporization of water into the air space in the sample holder upon opening is $q_{\mathrm{vap}} . \Delta T_{\text {reaction }}=\Delta T-E I t$ $\left(\frac{\epsilon_{i}+\epsilon_{f}}{2}\right)^{-1}$ where $\Delta T$ (not given in table 3) is the net temperature change resulting from the endothermic solution reaction and the electrical energy added, EIt. $q_{\text {vap }}=$ $\Delta H_{\mathrm{vap}}\left(V-\frac{s}{d}\right)(1-R H)$ where $\Delta H_{\text {vap }}$ is the enthalpy of vaporation of water per unit volume at the mean temperature of reaction, $\mathrm{V}$ is the internal volume of the sample holder, $s$ is the mass of sample, $d$ is the density of the sample, and $\mathrm{RH}$ is the relative humidity of the atmosphere in which the sample was transferred to the sample holder (for the transfer in the dry box, $R H=0$, in the laboratory atmosphere, $R H$ $=0.35 \pm 0.10)$. The enthalpy of solution per gram at the temperature of reaction and at the concentration of the measurements is $\Delta H_{m}(T)=-Q_{\text {reaction }}$ (Sample mass) ${ }^{-1}$. The methods of calculating the electrical energy equivalents, $\epsilon$, the corrected temperature change, $\Delta T$, and the electrical energy added during the reaction, EIt, were described previously $[11,12]$.

The change in the enthalpy of solution with temperature, $\Delta C_{p}$, was obtained from the data for $\Delta H(T)$ and $T_{\text {reaction }}$ for
Expt. Nos. 1152-1158 which are plotted in figure 1. A least squares fit of the data for $\Delta H(T)$ versus $\left(T_{\text {reaction }}-298.15\right.$ K) to a linear equation in the range $296 \mathrm{~K}<\mathrm{T}<328 \mathrm{~K}$, resulted in the intercept, $(24.07 \pm 0.15) \mathrm{kJ} \cdot \mathrm{mol}^{-1}$, and the slope $(0.1056 \pm 0.0099) \mathrm{kJ} \cdot \mathrm{mol}^{-1} \cdot \mathrm{K}^{-1}$. The uncertainties are the standard errors and the standard error of the estimate is $0.27 \mathrm{~kJ} \cdot \mathrm{mol}^{-1}$. The value, $\Delta C_{p}=(106 \pm 26)$ $\mathrm{J} \cdot \mathrm{mol}^{-1} \cdot \mathrm{K}^{-1}$, was used in computing the correction given in table 3 to obtain $\Delta H(298.15 \mathrm{~K})$.

In figure 2 are plotted the data for $\Delta H(298.15 \mathrm{~K})$ versus concentration for the 26 experiments listed in table 3 . The radius of a circle (or a circle circumscribed by the other geometric figures) is equal to the estimated calorimetric uncertainty for the experiment. There appears to be no significant change in the enthalpy of solution in the concentration range of 5 to $35 \mathrm{mmol} \cdot \mathrm{kg}^{-1}$; this is most evident from the open circles (Thy 3 ) where the one sample was used over the range.

The Karl Fischer titrations (see sec. 2.1.1) indicated little difference in the $\mathrm{H}_{2} \mathrm{O}$ content of the four commercial samples (Thy 1, Thy 2, Thy 3, and Thy 4) as received. In the calorimetric experiments given in table 3, all samples had been vacuum dried and were assumed to contain no $\mathrm{H}_{2} \mathrm{O}$, except Thy 3 which was used as received. A correction, 0.20 $\mathrm{kJ} \cdot \mathrm{mol}^{-1}$, for $0.83 \mathrm{~mol}$ percent $\left(0.12\right.$ mass \%) $\mathrm{H}_{2} \mathrm{O}$ was later applied to the values of $\Delta H(298.15 K)$ for Thy 3 given in table 3 , but it is not shown in figure 2 . There appears to be no significant difference between the enthalpies of solution for the recrystallized samples (the upper and lower halfshaded circles) and the parent material (open circles); this

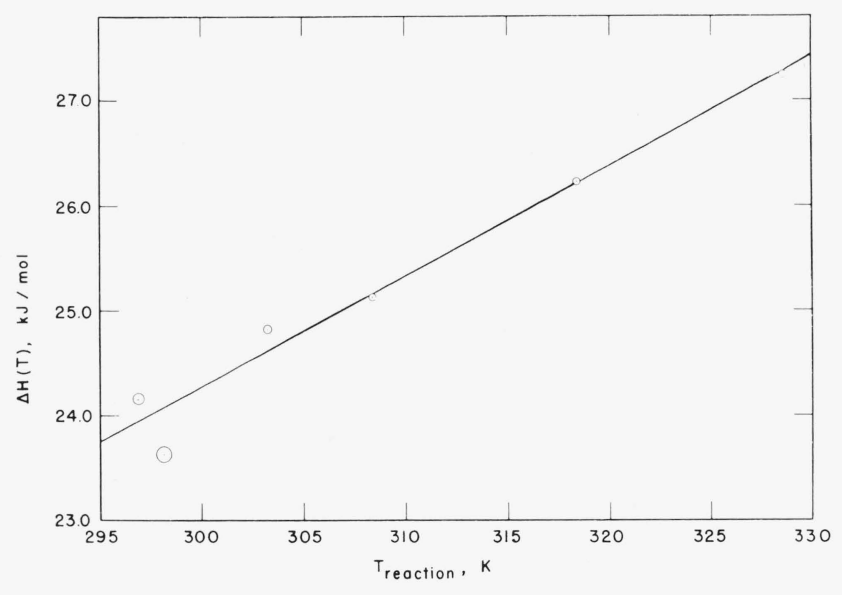

Figure 1. Plot showing the relationship between the temperature of reaction and the enthalpy of solution of thymine in $\mathrm{H}_{2} \mathrm{O}$.

The line [slope $\left.=\Delta \mathrm{Cp}=(106 \pm 26) \mathrm{J} \cdot \mathrm{mol}^{-1} \cdot \mathrm{K}^{-1}\right]$ represents the fit of the data by a least squares method. The estimated calorimetric uncertainty (see text) is equal to the radius of a circle. 


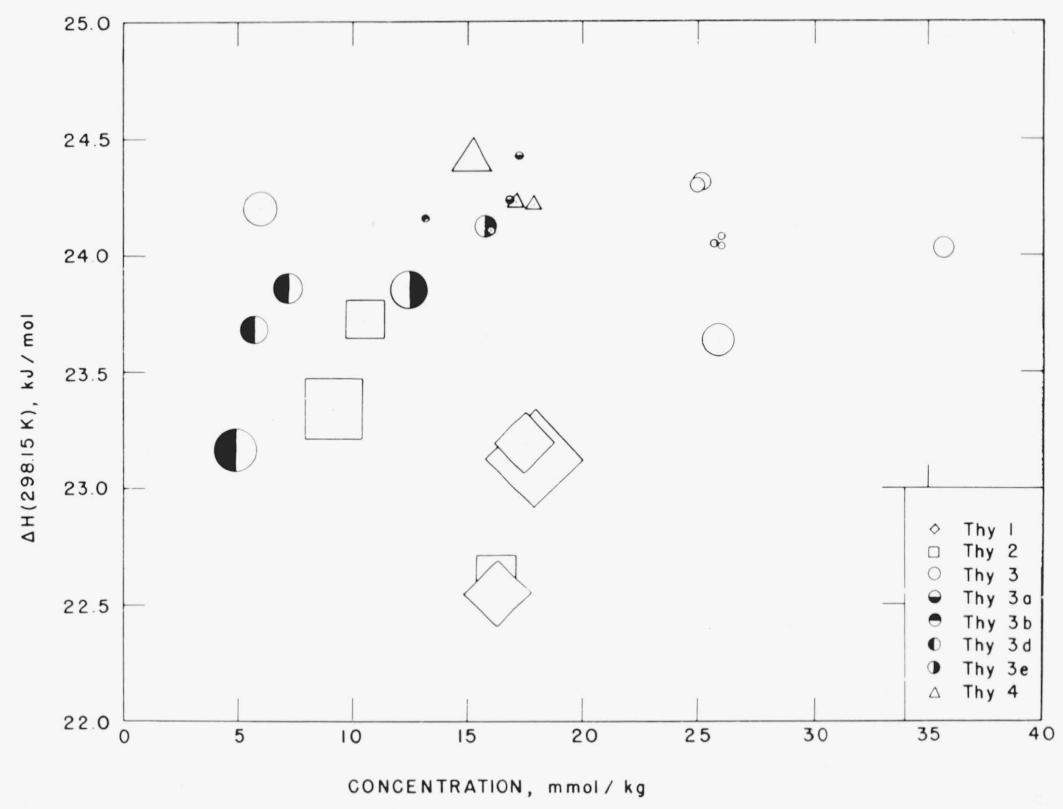

Figure 2. Plot showing the effect of concentration on the enthalpy of solution of various thymine samples in $\mathrm{H}_{2} \mathrm{O}$ at $298.15 \mathrm{~K}$.

The estimated calorimetric uncertainty (see text) is equal to the radius of a circle or a circle circumscribed by the other geometric figures.

probably indicates the Thy 3 was of high purity. However, the values for Thy 1 (diamonds), Thy 3 (squares), and the sublimed sample, Thy 3d (left half-shaded circles), are lower than most of the others; their calorimetric uncertainties are larger primarily because of the longer reaction periods.

If the sublimed sample, Thy $3 \mathrm{~d}$ (left half-shaded circles), were drier than the others shown in figure 2 , its enthalpy of solution should have a higher value than the others. Because lower values were measured, we conclude that some decomposition occurred during sublimation or the sublimed material was of a lower degree of crystallinity or a different tautomeric form as was found for sublimed adenine [1]; however, the magnitude of the difference in the enthalpies of solution of sublimed and unsublimed thymine $\left(\sim 1 \mathrm{~kJ} \cdot \mathrm{mol}^{-1}\right)$ was about one-fifth that for adenine. The two experiments with the unsublimed residue of sublimation, Thy $3 \mathrm{e}$ (right half-shaded circles), are borderline values and provide no conclusive information.

The one low value for Thy 3 (Expt. No. 1154) was probably the result of incomplete reaction. Some undissolved material remained at the end of the experiment, the slope of the rating period following the reaction was about 1 percent less than those of the preceeding and subsequent rating periods; and the length of the reaction period was only approximately twothirds that of the following similar experiment at a slightly lower temperature. Therefore, this experiment was omitted from the averages. The measurements with Thy 4 (triangles) agree well with those of Thy $3,3 \mathrm{a}$, and $3 \mathrm{~b}$.

On the assumption that the highest values for the enthalpy of solution represent the purest samples and the most complete reaction, we take as our best value the mean of the results of eight Thy 3 experiments (corrected for $\mathrm{H}_{2} \mathrm{O}$ and omitting Expt. No. 1154), two Thy 3a experiments, and three Thy 4 experiments. Thus $\Delta H(\infty, 298.15 \mathrm{~K})=(24.32 \pm$ $0.09) \mathrm{kJ} \cdot \mathrm{mol}^{-1}$. The uncertainty is the experimental imprecision at the 99 percent confidence level or 3.0 (standard deviation of the mean). An estimated uncertainty of 0.61 $\mathrm{kJ} \cdot \mathrm{mol}^{-1}(2.5 \%)$ is added for undetected impurities in the spectroscopic or chromatographic analyses and the unexplained differences in the elemental analyses. The sum of these uncertainties is $0.70 \mathrm{~kJ} \cdot \mathrm{mol}^{-1}(3 \%)$ which is taken as the overall uncertainty for the enthalpy of solution.

Alvarez and Biltonen [6] have shown that the enthalpy of solution of thymine in water is independent of concentration in the range, 0.8 to $8 \mathrm{mmol} \cdot \mathrm{kg}^{-1}$, and we have found this to be true from about 5 to $35 \mathrm{mmol} \cdot \mathrm{kg}^{-1}$. The ionization constant for the $\mathrm{N}_{3}$ proton [2] is about 4 orders of magnitude larger than the $\mathrm{H}^{+}$concentration of the final solutions in these measurements. Therefore, we assume there is no significant amount of ionization in the range of these measurements, and the enthalpies of solution can be taken as the values at infinite dilution for unionized thymine. 


\begin{tabular}{|c|c|c|c|c|c|c|c|c|c|c|c|c|c|c|c|c|}
\hline $\begin{array}{l}\text { Expt. } \\
\text { No. }\end{array}$ & $\begin{array}{c}\text { Sample } \\
\text { Mass } \\
\times 10^{5} \\
\end{array}$ & $\begin{array}{c}\mathrm{H}_{2} \mathrm{O} \\
\operatorname{Mass}-300_{8}\end{array}$ & \multirow{2}{*}{\begin{tabular}{|c}
$\begin{array}{c}\text { Final } \\
\text { Concentration } \\
\times 10^{6}\end{array}$ \\
$\mathrm{~mol} / \mathrm{kg}$
\end{tabular}} & \multirow{2}{*}{$\frac{{ }^{\mathrm{T}} \text { reaction }}{K}$} & \multirow{2}{*}{$\frac{\begin{array}{c}\text { Reaction } \\
\text { Period }\end{array}}{m 1 n}$} & \multirow{2}{*}{$\begin{array}{l}\text { Cal. } \\
\text { unc. } \\
\times 10^{2}\end{array}$} & \multicolumn{2}{|c|}{$\begin{array}{l}\text { Electrical Energy } \\
\text { Equivalent-1730 J/ K } \\
\text { Initial Final }\end{array}$} & \multirow{2}{*}{$\frac{\begin{array}{c}-\mathrm{T}_{\text {rea }} \\
\times 10^{5}\end{array}}{k}$} & \multirow{2}{*}{\begin{tabular}{|c|}
$\begin{array}{c}E I t \\
\times 10^{2}\end{array}$ \\
$J$
\end{tabular}} & \multirow{2}{*}{$\frac{\begin{array}{l}a_{-q_{v a p}} \\
\times 10^{2}\end{array}}{J}$} & \multirow{2}{*}{$\begin{array}{c}-\begin{array}{c}- \text { Qreaction } \\
\times 10^{2}\end{array} \\
J\end{array}$} & \multicolumn{2}{|c|}{$\Delta H(T)$} & \multirow{2}{*}{$\frac{\begin{array}{c}\text { Corr. to } \\
\mathrm{I} \text {. } \\
298.15 \mathrm{~K}\end{array}}{\mathrm{~J} / \mathrm{mol}}$} & \multirow{2}{*}{$\frac{\Delta \mathrm{H}(298.15 \mathrm{~K})}{\mathrm{J} / \mathrm{ml}}$} \\
\hline & 8 & 8 & & & & & & $\mathrm{~J} / \mathrm{k}$ & & & & & $\mathrm{J} / \mathrm{s}$ & $\mathrm{J} / \mathrm{mol}$ & & \\
\hline \multicolumn{17}{|c|}{ Thy 1: Calb1ochem Lot 900490} \\
\hline 1168 & 66723 & 2.434 & 17494 & 313.402 & 198 & 39 & 7.94 & 7.12 & 7563 & 87483 & 20 & 13121 & 196.65 & 24800 & 1611 & 23189 \\
\hline$\star 1169$ & 68209 & 2.414 & 17884 & 313.384 & 237 & 65 & 7.65 & 7.22 & 7708 & 86848 & 20 & 13372 & 196.04 & 24724 & 1609 & $23115 *$ \\
\hline 1170 & 62018 & 2.394 & 16262 & 313.402 & 227 & 44 & 6.48 & 6.76 & 6852 & | 86230 & 20 & 11878 & 191.52 & 24154 & 1611 & 22543 \\
\hline \multicolumn{17}{|c|}{ Thy 2: Mann Lot R-1282 } \\
\hline *1165 & 34971 & 2.349 & 9171 & 314.132 & 117 & so & 5.82 & 5.07 & 4012 & 86318 & 23 & 6940 & 198.45 & 25027 & 1688 & $23339 *$ \\
\hline$\star 1166$ & 40129 & 2.394 & 10522 & 313.470 & 102 & 34 & 6.26 & 5.85 & 4658 & 86878 & 22 & 8064 & 200.95 & 25343 & 1618 & $23725 *$ \\
\hline *1167 & 62203 & 2.349 & 16313 & 313.404 & 202 & 36 & 7.21 & 6.60 & 6886 & 86975 & 20 & 11941 & 191.97 & 24210 & 1582 & $22628 *$ \\
\hline \multicolumn{17}{|c|}{ Thy 3: E-M Lot 4955541 } \\
\hline 1152 & 99116 & 2.404 & 25989 & 318.457 & 37 & 6 & 7.92 & 8.54 & 11871 & 86138 & 23 & 20612 & 207.96 & 26226 & 2144 & 24082 \\
\hline 1153 & 97813 & 2.384 & 25649 & 308.330 & 67 & 7 & 6.30 & 6.05 & 11231 & 85472 & 14 & 19486 & 199.22 & 25124 & 1075 & 24049 \\
\hline$\star 1154$ & 98724 & 2.419 & 25885 & 298.109 & 97 & 28 & 5.04 & 4.71 & 10667 & 85591 & 8 & 18499 & 187.38 & 23631 & -4 & $(23635) *$ \\
\hline *1155 & 95734 & 2.429 & 25100 & 296.860 & 152 & 17 & 4.23 & 4.33 & 10410 & -.... & 8 & ${ }^{b}{ }_{18352}$ & 191.70 & 24176 & -136 & $24312^{\star}$ \\
\hline 1157 & 98989 & 2.359 & 25960 & 303.236 & 107 & 12 & 5.17 & 5.17 & 11242 & 87580 & 11 & 19495 & 196.94 & 24837 & 537 & 24300 \\
\hline$\star 1158$ & 99211 & 2.384 & 26016 & 328.511 & 27 & 6 & 10.62 & 11.31 & 12333 & 86119 & 36 & 21434 & 216.04 & 27246 & 3206 & $24040^{\star}$ \\
\hline 1159 & 136090 & 2.434 & 35680 & 313.374 & 37 & 18 & 7.93 & 6.85 & 15937 & 88924 & 16 & 27672 & 203.34 & 25644 & 1608 & 24036 \\
\hline$\star 1160$ & 61066 & 2.369 & 16014 & 313.413 & 22 & 6 & 6.13 & 5.97 & 7184 & 86782 & 20 & 12451 & 203.89 & 25714 & 1612 & $24102^{\star}$ \\
\hline 1161 & 19428 & 2.394 & 5094 & 313.189 & 32 & 30 & 6.10 & 5.33 & 2302 & | ---- & 23 & 3973 & 204.50 & 25790 & 1588 & 24202 \\
\hline \multicolumn{17}{|c|}{ Thy 3a: Tw1ce recrystallized from $\mathrm{H}_{2} \mathrm{O}$} \\
\hline 1175 & 64086 & 2.394 & 16804 & 313.437 & 27 & 6 & 6.98 & 7.05 & 7568 & 89606 & 20 & 13127 & 204.83 & 25832 & 1614 & 24218 \\
\hline 1176 & 65771 & 2.359 & 17248 & 298.402 & 47 & 9 & 5.35 & 4.58 & 7356 & | 89131 & 9 & 12754 & 193.92 & 24456 & 27 & 24429 \\
\hline \multicolumn{17}{|c|}{ Thy 3b: Twice recrystallized from EtoH } \\
\hline 1178 & 50214 & 2.354 & 13169 & 313.440 & 22 & 6 & 6.83 & | 6.52 & 5922 & 87606 & 21 & 10263 & 204.38 & 25776 & 1615 & 24161 \\
\hline \multicolumn{17}{|c|}{ Thy 3d: Sub11med } \\
\hline$\star 1179$ & 18425 & 2.339 & 4832 & 313.228 & 39 & 43 & 6.69 & 5.72 & 2104 & ----- & 35 & 3617 & $\mid 196.31$ & 24757 & 1592 & $23165 \star$ \\
\hline 1180 & 27427 & 2.399 & 7192 & 313.602 & 72 & 24 & 7.34 & 6.87 & 3212 & -..- & 35 & 5544 & 202.14 & 25492 & 1632 & 23860 \\
\hline$\star_{1181}$ & 21587 & 2.404 & 5660 & 313.231 & 67 & 25 & 6.49 & 6.00 & 2512 & |---- & 35 & 4327 & 200.44 & 25279 & 1592 & $23686 *$ \\
\hline \multicolumn{17}{|c|}{ Thy 3e: Sublimation residue } \\
\hline 1182 & 60245 & 2.379 & 15798 & 313.175 & 117 & 20 & 6.67 & 6.54 & 7092 & |---- & 32 & 12283 & 203.88 & 25713 & 1587 & 24126 \\
\hline 1183 & 47593 & 2.364 & 12481 & 313.214 & 157 & 34 & 6.59 & 6.07 & 5550 & |---. & 33 & 9603 & 201.77 & 25446 & 1591 & 23855 \\
\hline \multicolumn{17}{|c|}{ Thy 4: E-M Lot 4958785} \\
\hline 1171 & 65155 & 2.379 & 17086 & 313.418 & 47 & 10 & 7.41 & 6.91 & 7696 & 86930 & 20 & 13348 & 204.88 & 25838 & 1612 & 24226 \\
\hline 1172 & 68062 & 2.394 & 17847 & 313.425 & 52 & 8 & 7.32 & 7.09 & 8035 & 88414 & $2 n$ & 13939 & 204.80 & 25828 & 1613 & 24215 \\
\hline 1174 & 57812 & 2.424 & 15158 & 313.439 & 117 & 19 & 6.96 & 6.46 & 6880 & 87665 & 21 & 11929 & 206.34 & 26023 & 1614 & 24408 \\
\hline
\end{tabular}

"Sman11 amount of und1ssolved sample visible at end of these experiments - either trapped in alr bubble in sample container or floating on surface.

a The sample holder was filled with Thy $3 \mathrm{~d}$ and $3 \mathrm{e}$ in a glove box (relative humidity -0 ); it was filled with all other samples in the atmosphere (relative
humidity $-0.35 \pm .10$ ).

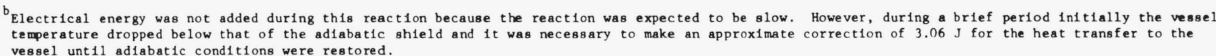

\section{Discussion and Summary}

The only direct measurements of the enthalpy of solution of thymine in water previously published were those of Alvarez and Biltonen [6]. They point out that about one-third of their measurements were rejected because of visible undissolved sample in the final solutions. Their value for $\Delta H$ $(298.15 \mathrm{~K}),(22.70 \pm 0.46) \mathrm{kJ} \cdot \mathrm{mol}^{-1}$, is lower but within the uncertainty limits of the mean of our three measurements on their sample (Thy 2 in table 3 ), $23.23 \mathrm{~kJ} \cdot \mathrm{mol}^{-1}$ with an average deviation of $0.40 \mathrm{~kJ} \cdot \mathrm{mol}^{-1}$. We experienced the difficulty of incomplete reaction with this material more than with the other samples used in this work. Alvarez and Biltonen [6] found $\Delta C_{p}=(188 \pm 17) \mathrm{J} \cdot \mathrm{mol}^{-1} \cdot \mathrm{K}^{-1}$ for this reaction; in this work, $\Delta C_{p}=(106 \pm 10) \mathrm{J} \cdot \mathrm{mol}^{-1} \cdot \mathrm{K}^{-1}$ was obtained from measurements with another sample, Thy 3 , which appears to be of higher purity than Thy 2 .

Differences in the enthalpies of solution of various samples of thymine were detected which were not explained by our analytical results; this was also true for adenine [1]. Better analytical data must be obtained before values for the enthalpy of solution of higher accuracy and smaller overall uncertainty can be expected. Our best values for the enthalpy of solution and for the change in the heat capacity for the reaction of thymine in water are:

$$
\begin{gathered}
\Delta H^{\circ}(\infty, 298.15 \mathrm{~K})=(24.32 \pm 0.70) \mathrm{kJ} \cdot \mathrm{mol}^{-1} \\
\Delta C_{p}^{\circ}=(106 \pm 26) \mathrm{J} \cdot \mathrm{mol}^{-1} \cdot \mathrm{K}^{-1}, 296 \mathrm{~K}<\mathrm{T}<328 \mathrm{~K}
\end{gathered}
$$

Other useful thermodynamic data can be calculated with these values. Herskovits and Harrington measured solubilities in water of adenine, thymine, cytosine and uracil [4]; Scruggs et al. made similar measurements for all of these except thymine [5]. The values of Scruggs et al. at $298 \mathrm{~K}$ are consistently 13 to 15 percent higher than the comparable values of Herskovits and Harrington which may have systematic errors. We have estimated the solubility of thymine in water at $298 \mathrm{~K}$ to be $32 \mathrm{mmol} \cdot \mathrm{kg}^{-1}$ (based on the value of 
$27.8 \mathrm{mmol} \cdot \mathrm{kg}^{-1}$ [4] with an estimated uncertainty of 10 percent, and at 298.15 K we obtain for the solution process

$$
\Delta G^{\circ}=-R T \ln m=(8.5 \pm 0.8) \mathrm{kJ} \cdot \mathrm{mol}^{-1}
$$

$$
\Delta S^{\circ}=\frac{\Delta H^{\circ}-\Delta G^{\circ}}{T}=(53.1 \pm 3.6) \mathrm{J} \cdot \mathrm{mol}^{-1} \cdot \mathrm{K}^{-1} .
$$

The apparent molal heat capacity at infinite dilution was calculated using $C_{p}^{\circ}$ given in section 2.1.3. as follows:

$$
C_{p 2}^{\circ}=\Delta C_{p}^{\circ}+C_{p}^{\circ}=(256 \pm 26) \mathrm{J} \cdot \mathrm{mol}^{-1} \cdot \mathrm{K}^{-1} .
$$

The author expresses her appreciation to R. L. Biltonen, of the University of Virginia, for his cooperation and interest in this work and for providing the sample of the same material on which his measurements were made.

\section{References}

[1] Kilday, M. V., Enthalpies of Solution of the Nucleic Acid Bases.
I. Adenine in Water, J. Res. Nat. Bur. Stand. (U.S.), 83, No. 4, 347-370 (July-August 1978).

[2] Izatt, R. M., Christensen, J. J., and Rytting, J. H., Chem. Rev. 71, 439-481 (1971).

[3] Robinson, D. R., and Grant, M. E., J. Biol. Chem. 241, 4030-4042 (1966).

[4] Herskovits, T. T., and Harrington, J. P., Biochem. 11, 4800-4810 (1972).

[5] Scruggs, R. L., Achter, E. K., and Ross, P. D., J. Am. Chem. Soc. 92, 2929-2936 (1970).

[6] Alvarez, J., and Biltonen, R., Biopolymers 12, 1815-1828 (1973).

[7] Ozeki, K., Sakabe, N., and Tanaka, J., Acta, Cryst. B25 1038-1045 (1969).

[8] Falk, M., Can. J. Chem. 43, 314-318 (1965).

[9] Committee on Specifications and Criteria for Biochemical Compounds, "Specifications and Criteria for Biochemical Compounds," Third Edition, National Academy of Sciences, Washington, D.C. (1972).

[10] Biltonen, R. L., Department of Pharmacology, University of Virginia School of Medicine, Charlottesville, VA, private communication, July 1977.

[11] Prosen, E. J., and Kilday, M. V., J. Res. Nat. Bur. Stand. (U.S.), 77A (Phys. and Chem.) No. 2, 179-203 (1973).

[12] Prosen, E. J., and Kilday, M. V., J. Res. Nat. Bur. Stand. (U.S.) 77A (Phys. and Chem.) No. 5, 581-597 (1973).

[13] Commission on Atomic Weights, Pure and Applied Chem. 47, 75-95 (1976). 